
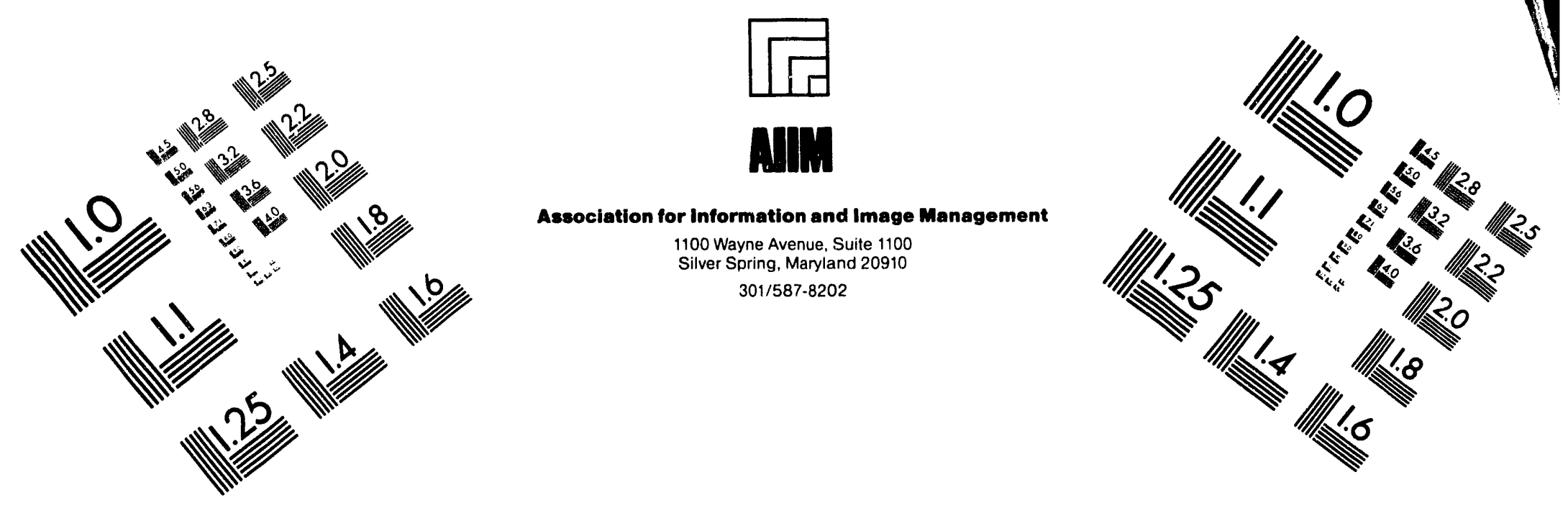

\title{
Centimeter
}

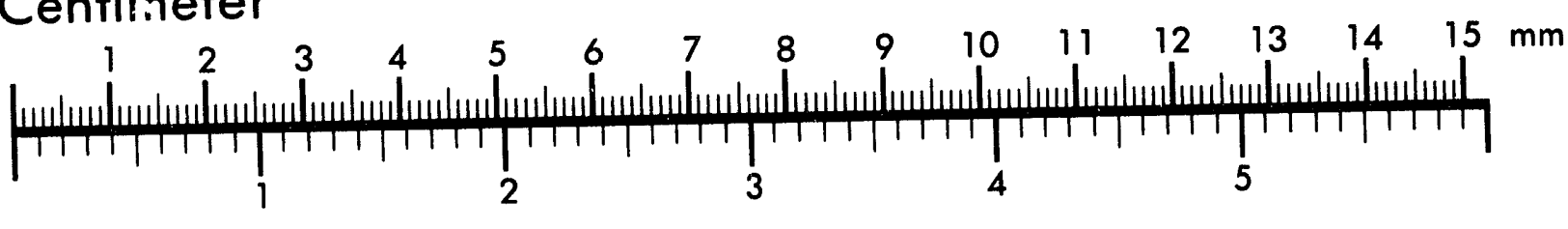
Inches
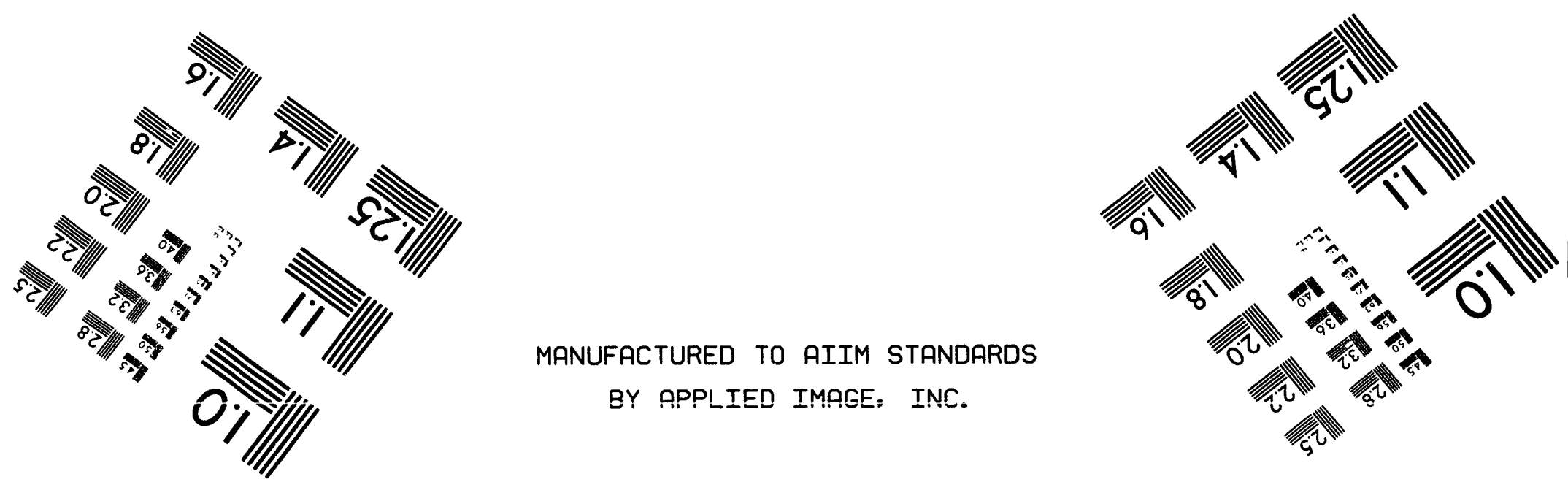

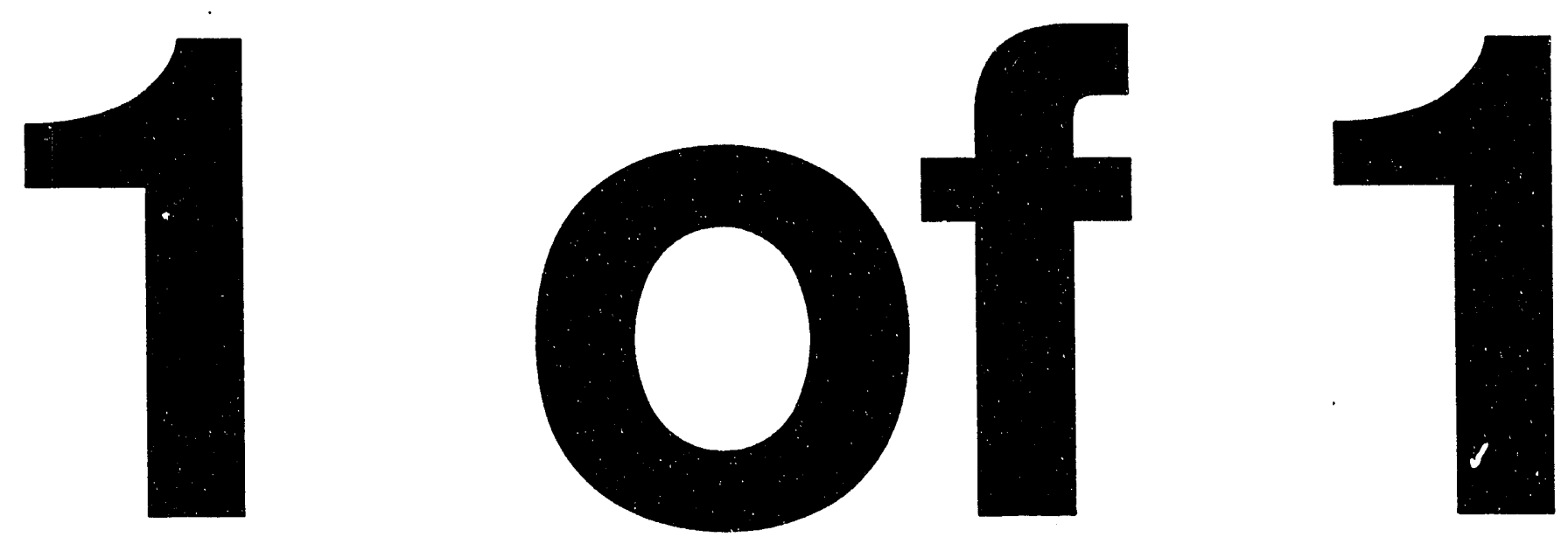


\section{STUDY OF MECHANICAL BEHAVIOR AND INTERNAL STRUCTURE \\ OF FERRITIC NANOCRYSTALLINE MATERIAL}

Technical Progress Report

For period 1 August 1992 - 1 March 1993

J. R. Weertman, Principal Investigator

walter P. Murphy Professor of Materials Science and Engineering

Northwestern University

Evanston, IL 60208-3108

March 1993

THE U.S. DEPARTMENT OF ENERGY

UNDER CONTRACT DE-FG-02-86ER45229

\section{NOTICE}

This report was prepared as an account of work sponsored by the United States Government. Neither the United States nor the Department of Energy, nor any of their employees, nor any of their contractors, subcontractors, or their employees, makes any warranty, express or implied, or assumes any legal liability of responsibility for the accuracy, completeness, or usefulness of any information, apparatus, product or process disclosed or represents that its use would not infringe privately-owned rights. 


\section{ABSTRACT}

\section{TECHNICAL PROGRESS REPORT}

\section{AUGUST 1992 TO 1 MARCH 1993}

Investigation has continued of the effect of heat treatment on the strength and on the internal structure of nanocrystaliine metals. It is found chat low temperature annealing increases the microhardness of ranocrystalline Pd. The anomalous Hall-Petch effect reported in the literature is the result of strengthening of as-compacted nanocrystalline material by annealing. Tests made up entirely of as-compacted samples or entirely of heattreated speiimens show a normal dependence of strength on grain size. $X$-Ray neasurements show that short range strains increase over the same range of annealing temperatures as the hardness while long range strains rapidly drop. SANS measurements of ascompacted and annealed nanocrystalline Pd gave quantitative information on the size and number density of a class of scatterers identified with triple point pores and of a class of larger scatterers interpreted as pores associated with "missing" grains. A new compaction unit has been designed and built that should produce larger samples with greatly reduced flaw content and lowered environmental contamination. 


\section{TECHNICAL PROGRESS REPORT FOR THE PERIOD \\ 1 AUGUST 1992 TO 1 MARCH 1993}

The research thrust of this grant has been directed into two areas. The principal effort has been spent in an investigation of the synthesis, mechanical behavior and internal structure of nanocrystalline material. A second effort involves a study of the high temperature behavior of several ferritic steels. In particular, we are investigating the precursors and earliest stages of fatigue crack initiation, especially how initiation is affected by hold times and by environment.

\section{NANOCRYSTALLINE MATERIAL}

Recently we have been investigating the strengthening effects of certain heat treatments on as-compacted nanocrystalline material. Such heating effects can lead to an apparent "negative Hall-Petch slope". Briefly, as described in our previous Progress Report, a number of workers [e.g., 1-3] have reported that at the finest grain sizes, the hardness of nanocrystalline metals drops markedly with decreasing grain size. Various explanations have been put forth to explain this anomalous behavi ir $[e . g ., 3,4]$. A literature survey we carried out seemed to indicate that a negative Hall-petch slope is most likely to be observed when the dependence of hardness $\mathrm{H}_{\mathrm{V}}$ on grain size d is obtained by use of a single, originally fine-grained sample that is repeatedly heated to obtain a series of grain sizes. studies in which only as-prepared material was used generally reported normal Hall-Petch behavior [5-7]. (All of the samples we had used were in the as-compacted state, and we consistently have found a positive slope of $\mathrm{H}_{\mathrm{v}}$ or yield strength $\mathrm{vs} \mathrm{d}^{-1 / 2}$.) To test this hypothesis, Gretchen Fougere [8] has taken samples of $\mathrm{Pd}$ and of $\mathrm{Cu}$ and measurea the effect of repeated annealings on their grain size and hardness. Whereas the specimens in their as-compacted state all corresponded to points on $\mathrm{H}_{\mathrm{v}} \mathrm{vs}$ d curves 
with positive slopes, the heating produced an initial hardening as well as increased grain size. Only after extended annealing did a further increase in grain size lead to a decrease in hardness.

From this experiment [8] and from other evidence [9-11] it can be concluded that even a low temperature anneal changes the internal structure of as-prepared samples in such a way as to increase their hardness. At this point it is not clear what changes are taking place that increase $\mathrm{H}_{\mathrm{V}}$. Two of the possible causes are changes in internal strains with heating and changes in the flaw/pore population. These possibilities are being examined by X-ray diffraction (XRD) and small angle neutron scattering (SANS). Results of these studies to date are described below.

Changes in Internal strains and Hardness Produced by Heating.

Several series of nanocrystalline Pd samples have been subjected to various heat treatments and subsequent measurements made of their Vickers microhardness $\mathrm{H}_{\mathrm{v}}$, grain size and residual strain state. Each series was obtained by cutting an as-compacted nanocrystalline Pd disk into quarters. One quarter was given no further treatment while the other 3 were heated in pure argon for 100 minutes at various elevated temperatures (see Table 1). (In some cases the EDM cutting caused the loss of one or two of the quarters.) This procedure of quartering a disk led to very small samples but had the great advantage of insuring that the oloserved differences in the behavior of the quarters arose entirely from their thermal history and not from sample-to-sample variations. Table 2 shows the values obtained by XRD for the average grain size of sample series 15 and 16 using various methods of analysis: Scherrer and Fourier analysis of single and double peaks [31-33]. Except for the samples annealed at $800^{\circ} \mathrm{C}$ (158 and 168), agreement among the various Fourier analysis meth- 
ods is very good, $\pm \approx 1-2 \mathrm{~nm}$. (At the large grain sizes produced by the $800^{\circ} \mathrm{C}$ anneal, the errors in the peak-broadening methods for obtaining grain sizes becomes appreciable.) As expected, the Warren-Averbach method generally yields smaller values for the average grain size than does scherrer analysis, since the former is an area-averaging process and the latter is volume-averaging. In the results described below, the average grain size is taken to be the 111-222 double peak value.

Figure 1 shows the change in average grain size with temperature of anneal. Straight lines connect the data points, so care must be exercised in interpreting the plots. It is clear from Table 2 and Figure 1 that 100 minutes exposure to $100^{\circ} \mathrm{C}$ does not increase the average grain size, at least within the limits of accuracy of the XRD analysis. The effect of heat treatment on hardness is given in Figure 2. A clear increase in $\mathrm{H}_{\mathrm{V}}$ with annealing temperatures in the $100-200^{\circ} \mathrm{C}$ range and even up to $300^{\circ} \mathrm{C}$ is evident. The microhardness and grain size data have been combined to yield several Hall-petch type plots. Figure 3 is a Hall-Petch plot of the as-compacted samples only. The slope $\mathrm{k}$ has a value of $5.2 \mathrm{GPa} / \sqrt{ } \mathrm{nm} . \quad\left(\mathrm{H}_{\mathrm{v}}=\mathrm{H}_{\mathrm{o}}+\mathrm{k} / \mathrm{Vd}\right.$, where $\mathrm{H}_{\mathrm{o}}$ is a constant.) Figure 4 is a similar plot for all the annealed samples, and includes all annealing temperatures. It can be seen that $k$ again is positive and has a similar slope, $4.3 \mathrm{GPa} / \mathrm{Vnm}$, but $\mathrm{H}_{\mathrm{O}}$ has more than doubled. It is only when as-compacted and annealed samples are combined that the Hall-petch curves contain portions with negative slopes (Figure 5). Figure 6 illustrates the strengthening effects of annealing by comparing the hardness of an as-compacted specimen with that of a sample of similar grain size that had been annealed at $300^{\circ} \mathrm{C}$. It can be seen that the heat treatment produced about a $50 \%$ increase in $\mathrm{H}_{\mathrm{v}}$.

$x$-ray measurements were carried out in crder to examine a possible role of the internal strain state of the nanocrystalline samples in producing the observed changes in $\mathrm{H}_{\mathrm{V}}$ with temperature. 
Figure 7 shows preliminary results on average strains perpendicular to the surface in samples 15 and 16 as a function of annealing temperature. The results are extremely sensitive to the alignment of the samples in the diffractometer and so are subject to appreciable error, but it is evident that the near-surface region of the as-compacted samples is under a large tensile strain, and that this strain drops off to about zero with even a low temperature anneal. The RMS strains, obtained by the Warren-Averbach method [13] and taken over a coherence length of $4 \mathrm{~nm}$, are shown in Figure 8. Again, the data points are connected by straight lines. Although the results are subject to a very considerable error, it does appear that the short range RMS strains increase upon a low temperature anneal and then drop off. It is interesting and perhaps suggestive that these strains increase over the same temperature range as does $\mathrm{H}_{\mathrm{v}}$.

\section{SANS Measurements.}

SANS measurements were carried out in January 1993 on the same nanocrystalline Pd samples whose grain size and internal strains were studied by XRD. The strength changes associated with heating could result from the sintering of nanovoids, pores, and microcracks. SANS should be sensitive to the presence of these defects. The SANS experiments were performed on the $30 \mathrm{~m}$ SANS instrument at the cold Neutron Research Facility at NIST. Dr. John Barker of the CNRF staff (and a former member of this research group) assisted us with the measurements.

By varying both neutron wave length $\lambda$ and sample-to-detector distance, a $q$-range between 0.001 and $0.35 \mathrm{~A}^{-1}$ was covered. (The scattering vector $q=4 \pi \sin \theta / \lambda$, where $\theta$ is the Bragg angle.) Qualitatively, the samples show a general trend of extensive high-q scattering in the as-compacted samples (indicating the presence of very small features) that diminishes markedly after heat treatment. Especially significant quantitative re- 
sults were obtained from the four quarters of sample 16. (The results of the 15 series were in general agreement with those of 16, but the 15 series samples were so small that their counting statistics were poor. For all samples, the procedure of quartering a disk led to very small sample volumes in the beam [1/8" diameter aperture or smaller] and thus a degradation in counting statistics, but had the great advantage of insuring that the observed differences in the behavior of the four quarters arise entirely from their thermal history and not from sample-to-sample variations.)

Figure 9 shows a plot of $\ln I$ vs $q$ for the four 16 series samples. Here $I$ is the differential scattering cross section in absolute units. The loss of high-q scattering (i.e., a drop in the density of the smallest-size scatterers) is evident. The data were analyzed in terms of the limiting cases of (1) Guinier scattering, where the $q$ values are sufficiently small that the inequality $q R<\approx 1.2-1.5$ is satisfied, and (2) Porod scattering, where the inequality $q R>3$ holds. ( $R$ is the radius of the scatterers, which are assumed to be roughly equiaxed. The volume of a scatterer is $\mathrm{v}_{\mathrm{p}}$ and their number density is $\mathrm{N}_{\mathrm{p}} \cdot$ ) In the case of (1), I $\alpha \approx N_{p} v_{p}^{2} \exp \left(-q^{2} R^{2} / 5\right)$. Thus the slope of a plot uf In I vs $q^{2}$ gives the value of $R$ and the intercept gives $N_{p}$. When Porod conditions apply, $I \approx(S / V) q^{-4}$, where $S / V$ is the total surface area of the scatterers per unit sample volume. A plot of $q^{4} I$ vs $q$ should yield a straight line parallel to the $q-$ axis. Figure 10 is such a plot. It can be seen that porod behavior indeed occurs. However at high $q$ values, where the Porod scattering from a class of larger scatterers has fallen off, scattering from the smallest features becomes predominant. A Guinier plot of the scattering after subtraction of the Porod component is given in Figure 11. The slope indicates features with a radius of about $1 / 2 \mathrm{~nm}$, which is about at the lower limit of features detectable by SANS. The sizes and number densities (calculated on the assumption that these small scatterers are 
voids) are given in Table 3. Not only do these presumed voids have an appropriate diameter for triple point pores $[9,15]$ but their total volume follows closely the predictions of Palumbo et al. [15] based on geometric considerations.

The density of the original as-compacted disk, from which the four samples were cut, was measured to be 0.86 times the theoretical density for large grain Pd. This value, together with the volume fraction attributable to the triple point pores, allows an estimate to be made of the void volume fraction of the larger scatterers of the porod region of Figure 10. Combining the void volume fraction of the larger pores with their total surface area, obtained from the porod scattering, leads to a characteristic size of these larger pores of about $9 \mathrm{~nm}$. This value is close to the grain size of the as-compacted sample and may correspond to a "missing grain" in the compact. The number density of these larger pores is about $6 \times 10^{15} / \mathrm{cm}^{3}$, i.e., about $1 / 1000$ th of the number of grains per unit volume. It was not possible to calculate the size and number density of the larger voids after heat treatment, because the quartered disks were too small for density measurements.

The inset in Table 3, taken from the work of Schaefer [9], depicts two classes of defects we believe give rise to the sANS scattering. These are the triple point pores, corresponding to $\tau_{2}$ in the sketch, and the pores about the size of a missing grain, $\tau_{3}$. We do not believe that the observed scattering comes from defects in the interface (corresponding to $\tau_{1}$ ). This assumption is a departure from the past analysis of sANs from nanocrystalline material [e.g., 5]. This neglect of grain boundary scaltering is based on the observations that grain boundaries in FCC nanocrystalline metals are not so different from ordinary boundaries $[17,18]$ and the observation that ordinary boundaries, large numbers of vacancies, and subgrain boundaries do not perceptibly scatter long wave length neutrons $[19,20]$. Interpreta- 
tion of scattering data is model dependent. We believe that ours leads to results that are remarkably consistent with quantitative predictions about pores in nanocrystalline material and with known facts about scattering behavior.

It is evident from Figure 9 that there is a third class of scatterers present in the samples. These scatterers are larger in dimensions than the other two types, and produce the strong forward scattering that dies off rapidly as $q$ increases. This low $q$ scattering is likely to arise from microcracks and other comparatively large-scale flaws. We are very anxious to eliminate these large flaws so that we can measure the size and number density of the "missing grain" pores directly from their Guinier behavior, now masked by scattering from the flaws. We are very hoperul that the new compaction unit (see below) will solve this problem.

Scanning Tunneling Microscopy.

We have begun a collaboration with Professor Heinrich Jaeger at the University of chicago to examine our nanocrystalline samples by STM. His preliminary studies of our $\mathrm{Cu}$ and Pd samples are very promising. Examination of the 16 series of four Pd samples mentioned above shows that the size of the surface grains in the as-compacted sample is quite uniform and consistent with the $\mathrm{X}$-ray results, but that $800^{\circ} \mathrm{C}$ annealing leads to a mixture of large and still small grains. It is not clear at this stage what role a surface oxide may play in the growth of the surface grains.

In summary, internal strains and defect structure have been examined in nanocrystaline samples of $P d$ in both the ascompacted and heat treated state. It appears that the short range strains increase over the same annealing temperature range as the hardness while long range strains rapidly drop. Pore 
density also changes with annealing temperature. It has been shown that the anomalous Hall-petch slope is the result of strengthening of as-compacted nanocrystalline material by a low temperature anneal that affects internal strains and defect structure. At higher annealing temperatures the softening from the resultant grain growth overwhelms this strengthening effect. Tests made up entirely of as-compacted samples or entirely of heat-treated specimens show a normal dependence of strength on grain size.

The SANS experiments are being written up for publication. Both the SANS and hardness/internal strains/grain size results were presented at the 1993 Annual Meeting of TMS.

New Compaction Unit.

As indicated above, microcracks and flaws play a major role in the measured (extrinsic) mechanical strength of our nanocrystalline material. They also can affect the characterization results, as in the case of the large forward scattering in the SANS measurements. Increasing the accuracy of the SANS measurements requires larger volumes of material in the beam. In fact, almost all of the nanocrystalline experiments would benefit from larger sample size. Other measurements, not now feasible, would become possible, e.g., density measurements of the quarters of a series of annealed samples for the SANS measurements. For the study of nanocrystalline material that reacts with the environment, such as iron, it is essential to be able to deliver the compacted disk into an evacuated container that can be closed off under vacuum. For all of these reasons, an improved compaction unit is needed that provides for more efficient collection of powder, permits low temperature heating under increased pressure to assist in the elimination of microcracks and large flaws, and has better vacuum characteristics. 
During this reporting period Gretchen Fougere has been spending all her time at Argonne National Lab working on the design and overseeing the construction of a new compaction unit to be used both on the Joule-heated and the e-beam-heated inert gas condensation instruments at Argonne. The new compaction unit is a joint venture between Argonne and this research group, and was made possible by a supplement to this grant last year. A highly schematic drawing of the compaction unit is given in Figure 12. It is designed to fulfill the requirements mentioned above. Thanks in large part to the continuous pushing forward by Ms Fougere the unit is nearing completion and should be ready for operation in another week.

\section{ENVIRONMENT/HOLD TIME EFFECTS IN STEEL}

The goal of this work is to understand the influence of environment and hold pattern on the high temperature fatigue behavior of two chromium ferritic steels, Fe2.25Cr1Mo and Fe9Cr $1 \mathrm{Mo}+\mathrm{V}$, Nb.

This research was concluded during the report period. Two final papers (attached to this Technical Report) were written and submitted to Metallurgical Transactions A, and an earlier paper was published in the February 1993 issue of that journal (reprint attached). A presentation of the Fe9Cr1Mo+V, Nb work was made at the 1993 Annual Meeting of TMS. The graduate student working on this project, Rena Hecht, defended her PhD thesis and has taken a position in the Materials Lab at Ford Motors.

\section{REFERENCES}

1. K. Lu, W. D. Wei and J. T. Wang, Scripta Met. et Mater. 24, 2319 (1990).

2. T. Christman and M. Jain, Scripta Met. et Mater. $\underline{25}, 767$ (1991).

3. A. H. Chokshi, A. Rosen, J. Karch and H. Gleiter, Scripta Met 23,1679 (1989). 
4. T. G. Nieh and J. Wadsworth, Scripta Met. et Mater. 25, 955 (1991).

5. J.S. C. Jang and C. C. Koch, Scripta Met. et Mater. 24, 1599 (1990).

5. G. W. Nieman, J. R. Weertman, and R. W. Siegel, Scripta Met. 23, 2013 (1989).

7. S. K. Ganapathi and D. A. Rigney, Scripta Met. et Mater. 24, 1675 (1990).

8. G. E. Fougere, T. R. Weertman, R. W. Siegel and S. Kim, Scripta Met. et Mater. 26, 1879 (1992).

9. H.-E. Schaefer, in "Mechanical Properties and Deformation Behavior of Materials Having Ultra-Fine Microstructures", ed. M. A. Nastasi, Kluwer Academic Press, Dordrecht, The Netherlands, in press.

10. H. Gleiter, ibid.

11. R. Z. Valiev, F. Chmelik, F. Bordeaux, G. Kapelski and R. Baudelet, Scripta Met. et Mater. 27, 855 (1992).

12. B. E. Warren, "X-Ray Diffraction", Addison-Wesley, Reading, MA, 1969, p. 251 .

13. L. H. Schwartz and J. B. Cohen, "Diffraction from Materials", 2nd Ed., C. Springer-Verlag, Berlin, 1987, p. 372 .

14. A. Guinier, "X-Ray Diffraction in Crystals, Imperfect Crystals and Amorphous Bodies", W. H. Freeman and Co., San Francisco, 1970, p. 121.

15. G. Palumbo, S. J. Thorpe and K. T. Aust, scripta Met. et Mater. 24, 1347 (1990).

16. E. Jorra, H. Franz, J. Peisl, G. Wallner, W. Petry, R. Birringer, H. Gleiter and T. Haubold, Phil. Mag. B 60, 159 (1989).

17. G. J. Thomas, R. W. Siegel and J. A. Eastman, Scripta Met. et Mater. 24, 201 (1990).

18. J. A. Eastman, M. R. Fitzsimmons, M. Muller-Stach, G. Wallner and W. T. Elam, Nanostructured Mats. 1, 47 (1992).

19. R. Page, J. R. Weertman and M. Roth, Acta Met. 30, 1357 (1982).

20. M. Roth, J. Appl. Cryst. 10, 172 (1977) • 


\section{PLANS FOR THE BALANCE OF THE GRANT YEAR}

The new compaction unit should produce larger samples with fewer flaws. It is planned to continue the sANs investigation with these larger specimens that will allow measurements over a wider $q$ range because of the higher signal-to-noise ratio. Larger specimens will permit the density of the annealed "quarters" to be measured, and thus it will be possible to follow the influence of heating on the "missing grain" voids as well as on the triple point voids. If the flaws and microcracks are largely eliminated, the size and number density of the missing grain voids can be obtained directly from the low $\mathrm{q}$ scattering, and the total void volume fraction can be calculated from the invariant and compared with the density measurements. If all of the results prove to be consistent, it will be strong evidence that nanocrystalline grain boundaries are not significant contributors to small angle scattering and that these boundaries are not so different from grain boundaries in ordinary FCC metals. of course it also will help to validate the sANS conclusions on the pore populations in the nanocrystalline Pd.

Paul Sanders has almost completed a creep apparatus suitable for the nanocrystalline samples, and we plan to begin testing of nanocrystalline $\mathrm{Pd}$ and $\mathrm{Cu}$ samples to examine the mode of deformation at elevated temperatures. Our previous tests had shown that room temperature creep is negligible but a modest rise in temperature should bring diffusional creep into the measurable range. However the deformation mechanism may be dominated by grain boundary or lattice processes. Few data are available on the creep behavior of nanocrystalline metals. The internal strain measurements described in the previous section indicate that residual strains (and stresses) play an important role in determining the influence of annealing on strength. It is planned to continue the strain measurements, with special attention paid to 
the reproducibility of sample alignment. It may be necessary to do the annealing in situ in the $x$-ray equipment.

With the completion of the new compaction unit, Gretchen Fougere can resume her studies of the mechanical behavior of nanocrystalline iron and steel. With the current equipment it is impossible to obtain high density material, and what is produced is adversaly affected by exposure to the environment. The new unit should correct these problems.

Carl Youngdahl is continuing his study of composite nanocrystalline material using the e-beam apparatus for synthesis of the samples. Modifications are just being completed to this instrument, and it should be ready for materials synthesis in the immediate future.

\section{STATEMENT OF EFFORT}

The Principal Investigator is devoting $15 \%$ of her effort during the academic year to this project. During the summer $25 \%$ of her time is being devoted to it. Gretchen Fougere is in her third year of graduate school. She is working on nanocrystalline iron and steel. She is supported by Argonne National Lab. Carl Youngdahl and Paul sanders are in their second year of graduate studies and have essentially completed their class work. Carl is working on nanocrystalline composites and Paul on pure metals. Both are examining mechanical behavior and characterizing the internal structure of their materials, and attempting to relate strength to structure, especially defect structure. Mechanisms of deformation are of special interest.

In this work we are collaborating with Drs. Richard Siegel and Jeff Eastman at Argonne National Laboratory and Professor Heinrich Jaeger at the University of Chicago. 
DEGREES GRANTED, PAPERS, AND ORAL PRESENTATIONS DURING 6-MONTH REPORT PERIOD

\section{Degrees}

Rena Hecht received her $\mathrm{PhD}$ and now is working in the scientific Research Laboratory of Ford Motor Company in Dearborn, MI. The title of her thesis is "Mechanisms operating during High Temperature Fatigue with Hold Periods in Two chromium Ferritic steels".

Andrea wilford received her MS and now is working for the Nuclear Regulatory Commission. The title of her thesis is "Microscopy studies of Nanocrystalline $\mathrm{Pd}$ and $\mathrm{Cu}$ ".

\section{Paper Published}

"Periodic Oxide Cracking on Fe2.25Cr1Mo Produced by High Temperature Fatigue Tests with a Compression Hold", R. L. Hecht and J. R. Weertman, Metallurgical Transactions A 24A, 327 (1993).

\section{Papers in Press}

"Hall-Petch Behavior of Nanocrystalline Metals", J. R. Weertman, M. Niedzielka and C. Youngdahl, in Mechanical properties and Deformation Behaviour of Materials Having Ultra-Fine Microstructures, M. A. Nastasi, Ed., Kluwer Academic Press, Dordrecht, The Netherlands.

"SANS and TEM Studies of Isothermal $\mathrm{M}_{2} \mathrm{C}$ Carbide Precipitation in Ultrahigh Strength AF1410 steel", A. J. Allen, D. Gavillet and J. R. Weertman, Acta Metallurgica and Materialia.

"Hall-Petch strengthening in Nanocrystalline Metals", J. R. Weertman, Materials Science and Engineering.

\section{Submitted for Publication}

"Grain-Size Dependent Hardening and Softening of Nanocrystalline Materials", G. E. Fougere, J. R. Weertman and R. W. Siegel, 
submitted to Nanostructured Materials.

"High Temperature Fatigue with Hold Periods of Modified 9\%Cr1\%Mo steel", R. L. Hecht and J. R. Weertman, submitted to Metallurgical Transactions A.

"The Effect of Environment on High Temperature Hold Time Fatigue Behavior of Annealed $2.25 \% \mathrm{Cr} 1 \%$ Mo steel", R. L. Hecht and J. R. Weertman, submitted to Metallurgical Transactions A.

"A Gradient Method for Anomalous Small-Angle X-Ray Scattering", P. R. Jemian, J. R. Weertman and G. G. Long, submitted to Journal of Applied Crystallography.

\section{oral Presentations}

"Grain-Size Dependent Hardening and Softening of Nanocrystalline Metals", G. E. Fougere, J. R. Weertman and R. W. Siegel, First International Conference on Nanostructured Materials, Cancun, Mexico, 21-25 september 1992 .

* "Hall-Petch strengthening in Nanocrystalline Metals", J. R. Weertman, DOE Workshop: Grain Boundary and Interface Phenomena in the High Temperature Plasticity of Solids, Oakland, CA, 12-16 october 1992 .

* "Mechanical Properties of Nanocrystalline Metals", J. R. Weertman, University of Houston, Houston, TX, 2 February 1993.

"An Environmental-Fatigue Interaction in Modified Fe9crimo steel", R. L. Hecht and J. R. Weertman, TMS Annual Meeting, Denver, CO, 21-25 February 1993.

"Internal strains in Nanocrystalline Materials by X-Ray Techniques", P. Sanders, C. Youngdahl, G. E. Fougere, J. R. Weertman, and R. W. Siegel, TMS Annual Meeting, Denver, CO, 21-25 February 
"SANS and STM Studies of Nanocrystalline Palladium", P. Sanders, A. Wilford, and R. W. Siegel, TMS Annual Meeting, Denver, Co, 21-25 February 1993.

* (Upcoming) "Deformation of Nanocrystalline Metals", J. R. Weertman, Dislocations 93: Microstructures and Physical Properties, 31 March-9 April 1993, Aussois, France.

* Invited Lecture

SUMMARY OF PAPERS, PRESENTATIONS, AND DEGREES AWARDED OVER THE GRANT PERIOD TO DATE ( 2.5 YEARS).

\section{Degrees}

G. William Nieman, PhD, "Processing and Mechanical Behavior of Nanocrystalline $\mathrm{Cu}, \mathrm{Pd}$, and Ag" . Current employment: Allied signal, Des Plaines, IL.

Rena Hecht, PhD, "Mechanisms operating during High Temperature Fatigue with Hold Periods in Two Chromium Ferritic steels". current employment: Ford Motor Company.

Andrea Wilford, MS, "Microscopy Studies of Nanocrystalline Pd and cu". Current Employment: Nuclear Regulatory Commission.

Papers Published

"High-Resolution Small-Angle X-Ray Scattering Camera for Anomalous scattering", D. R. Black, H. E. Burdette, P. R. Jemian, G. G. Long and J. R. Weertman, J. Appl. Cryst. 24, 30 (1991).

"Characterization of Modified Fe9cr1Mo steel by Anomalous SmallAngle X-Ray Scattering", P. R. Jemian, J. R. Weertman, G. G. Long 
and R. D. Spal, Acta Metall. et Mater. 39, 2477 (1991).

"Grain-Size Dependent Hardening and Softening of Nanocrystalline $\mathrm{Cu}$ and Pd", Scripta Metall. and Mater. 261879 (1992).

"Periodic oxide Cracking on Fe2.25Cr1Mo Produced by High Temperature Fatigue Tests with a compression Hold", R. L. Hecht and J. R. Weertman, Metallurgical Transactions A 24A, 327 (1993).

\section{Papers in press}

"Hall-Petch Behavior of Nanocrystalline Metals", J. R. Weertman, M. Niedzielka and C. Youngdahl, in Mechanical Properties and Deformation Behaviour of Materials Having Ultra-Fine Microstructures, M. A. Nastasi, Ed., Kluwer Academic Press, Dordrecht, The Netherlands.

"SANS and TEM Studies of Isothermal $\mathrm{M}_{2} \mathrm{C}$ Carbide Precipitation in Ultrahigh strength AF1410 steel", A. J. Allen, D. Gavillet and J. R. Weertman, Acta Metall. and Mater.

"Hall-Petch strengthening in Nanocrystalline Metals", J. R. Weertman, Materials Science and Engineering.

\section{Submitted for publication}

"Grain-size Dependent Hardening and Softening of Nanocrystalline Materials", G. E. Fougere, J. R. Weertman and R. W. Siegel, submitted to Nanostructured Materials.

"High Temperature Fatigue with Hold Periods of Modified $9 \% \mathrm{Cr} 1 \%$ Mo steel", R. L. Hecht and J. R. Weertman, submitted to Metallurgical Transactions A.

"The Effect of Environment on High Temperature Hold Time Fatigue Behavior of Annealed $2.25 \% \mathrm{Cr} 1 \%$ Mo steel", R. L. Hecht and J. R. Weertman, submitted to Metallurgical Transactions A. 
"A Gradient Method for Anomalous small-Angle X-Ray Scattering", P. R. Jemian, J. R. Weertman and G. G. Long, submitted to Journal of Applied Crystallography.

\section{oral presentations}

* "Mechanical Behavior of Nanocrystalline Metals", National Research Institute of Metals, Tokyo, Japan, 13 December 1990.

* As above, MITI Group, Tokyo, Japan, 18 December 1990.

* As above, University of Kyoto, Kyoto Japan, 20 December 1990.

"Physical Properties and Mechanical Behavior of $\mathrm{Cu}$ Samples with Nanometer Grain sizes", TMS spring Meeting, New orleans, LA 19 February 1991.

* "Mechanical Behavior of Nanocrystalline Metals", University of Wisconsin, Madison, WI, 18 April 1991.

* As above, University of California at San Diego, San Diego, CA, 22 April 1991.

* As above, University of Chicago, Chicago, IL, 20 May 1991.

As above, TMS Fall Meeting, Cincinnati, OH, 24 October 1991.

* As above, Massachusetts Institute of Technology, Cambridge, MA, 14 November 1991.

* As above, Alcoa Technical Center, Alcoa, PA, 13 December 1991.

* As above, Westinghouse Research Laboratory, Pittsburgh, PA, 6 February 1992 . 
"The Effect of Environment and Hold Pattern on Fatigue Behavior of Fe9Cr1MoNbV steel Compared to Fe2.25Cr1Mo steel", TMS Annual Meeting, San Diego, CA 4 March 1992.

"Periodic Surface Cracking on Fe2.25Cr1Mo steel that Results from High Temperature Compressive Hold Fatigue Tests", R. L. Hecht and J. R. Weertman, TMS Annual Meeting, San Diego, CA, 4 March 1992.

* "Anomalous sAxs to study the High Temperature Behavior of a Carbide species in a complex steel", NSLS Workshop on SAXS for Materials Science, Brookhaven National Laboratory, Upton, NY, 18 May 1992 .

*"Hall-Petch Behavior in Nanocrystalline Metals", NATO Advanced study Institute on Nanostructured Materials, Vimiero, Portugal, 9 July 1992 .

"Grain-size Dependent Hardening and Softening of Nanocrystalline Metals", First International Conference on Nanostructured Materials, Cancun, Mexico, 21-25 September 1992.

* "Hall-Petch strengthening in Nanocrystalline Metals", DOE Workshop on Grain Boundary and Interface Phenomena in the High Temperature Plasticity of solids, Oakland, CA, 12-16 October 1992 .

* "Mechanical Properties of Nanocrystalline Metals", University of Houston, Houston, TX, 2 February 1993.

"An Environment-Fatigue Interaction in Modified Fe9cr1Mo steel", TMS Annual Meeting, Denver, CO, 21-25 February 1993.

"Internal strains in Nanocrystalline Materials by X-Ray Techniques", TMS Annual Meeting, as above. 
"SANS and STM Studies of Nanocrystalline Palladium", TMS Annual Meeting, as above.

* (Upcoming) "Deformation of Nanocrystalline Metals", Dislocations 93: Microstructures and Physical Properties, 31 March-9 April 1993, Aussois, France.

* Invited presentation 
TABLE 1. Heat Treatment, grain size, and Vickers microhardness Hv for the Pd samples used in the internal strains and SANS measurements. Samples were heated for 100 minutes.

\begin{tabular}{c|cccc}
$\begin{array}{c}\text { Sample } \\
\text { Number }\end{array}$ & $\begin{array}{c}\text { Heat } \\
\text { (C) }\end{array}$ & $\begin{array}{c}\text { Grain } \\
\text { Size (nm) }\end{array}$ & $\begin{array}{c}\text { Hv } \\
(\mathrm{GPa})\end{array}$ & $\begin{array}{c}\text { Std Dev } \\
(\mathrm{GPa})\end{array}$ \\
\hline \multirow{3}{*}{5} & 20 & 12 & 2.09 & 0.17 \\
& 200 & 22 & 2.27 & 0.27 \\
& 500 & 27 & 1.87 & 0.67 \\
& 800 & 52 & 1.13 & 0.18 \\
6 & 20 & 15 & 1.87 & 0.22 \\
& 300 & 32 & 2.27 & 0.16 \\
& 500 & 49 & 1.89 & 0.24 \\
& 700 & 50 & 1.70 & 0.18 \\
7 & & & & \\
& 20 & 6 & 3.07 & 0.31 \\
& 400 & 28 & 2.92 & 0.18 \\
& 600 & 39 & 2.55 & 0.33 \\
& & & & \\
& 20 & 4 & 2.97 & 0.14 \\
& 100 & 4 & 3.34 & 0.26 \\
& & & & \\
& 20 & 4 & 3.38 & 0.24 \\
& 100 & 4 & 3.74 & 0.46 \\
& 300 & 10 & 3.03 & 0.12 \\
& 800 & 125 & 1.94 & 0.16 \\
& & & & \\
& 20 & 5 & 2.68 & 0.18 \\
& 100 & 7 & 2.82 & 0.32 \\
& 300 & 18 & 2.70 & 0.16 \\
& 800 & 182 & 1.87 & 0.25
\end{tabular}




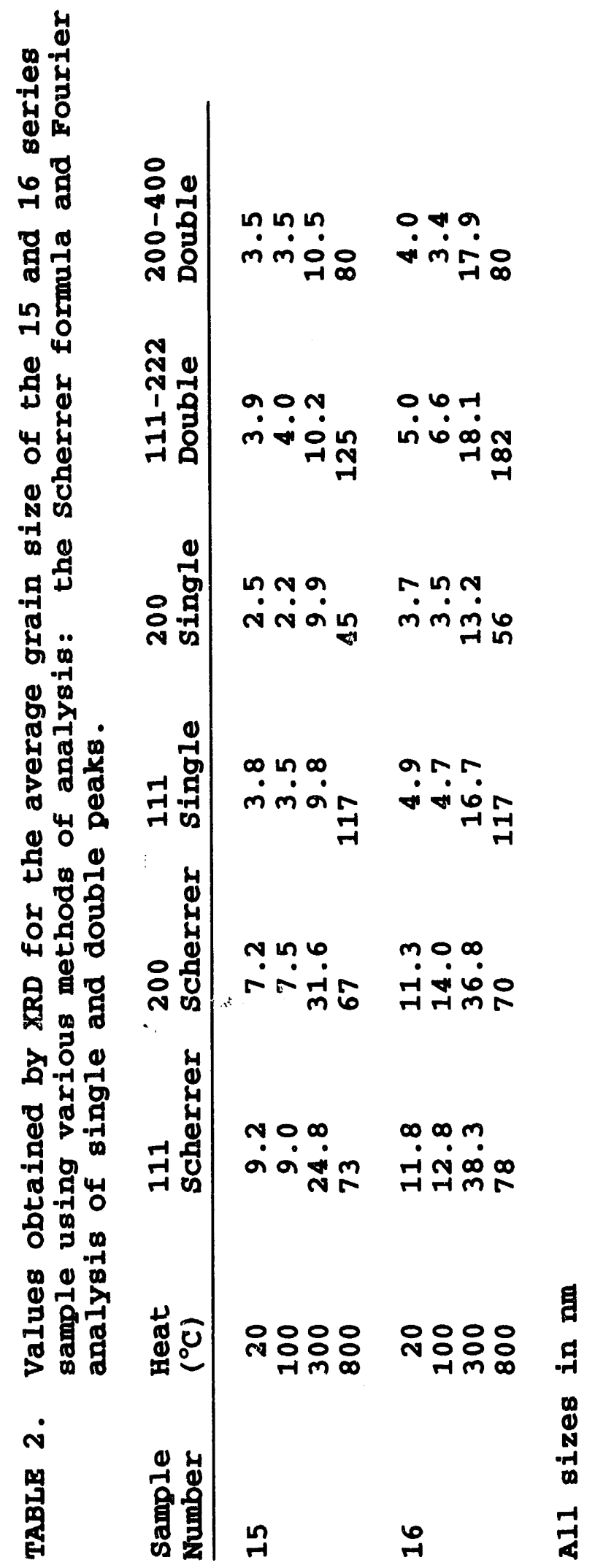




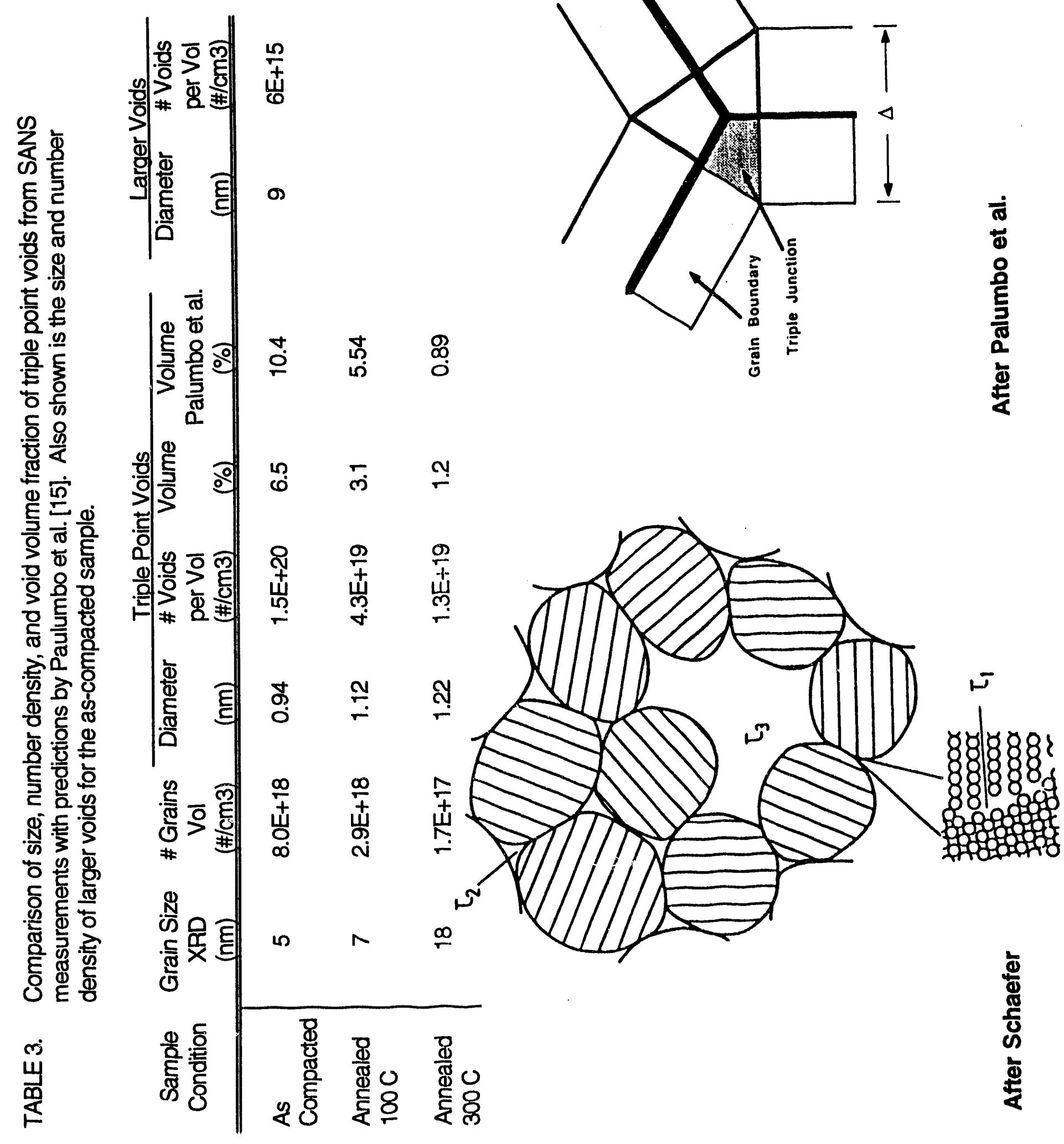




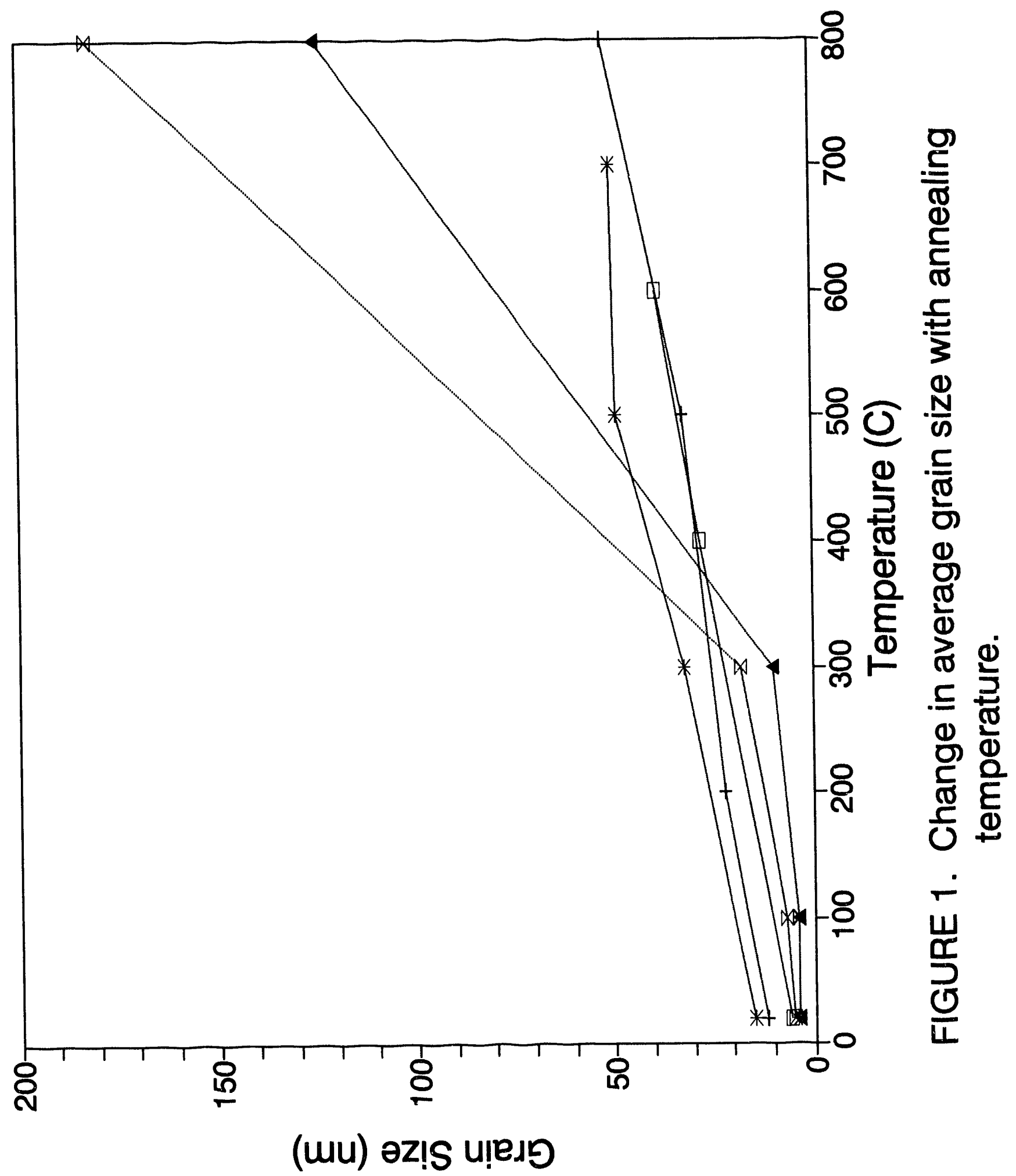




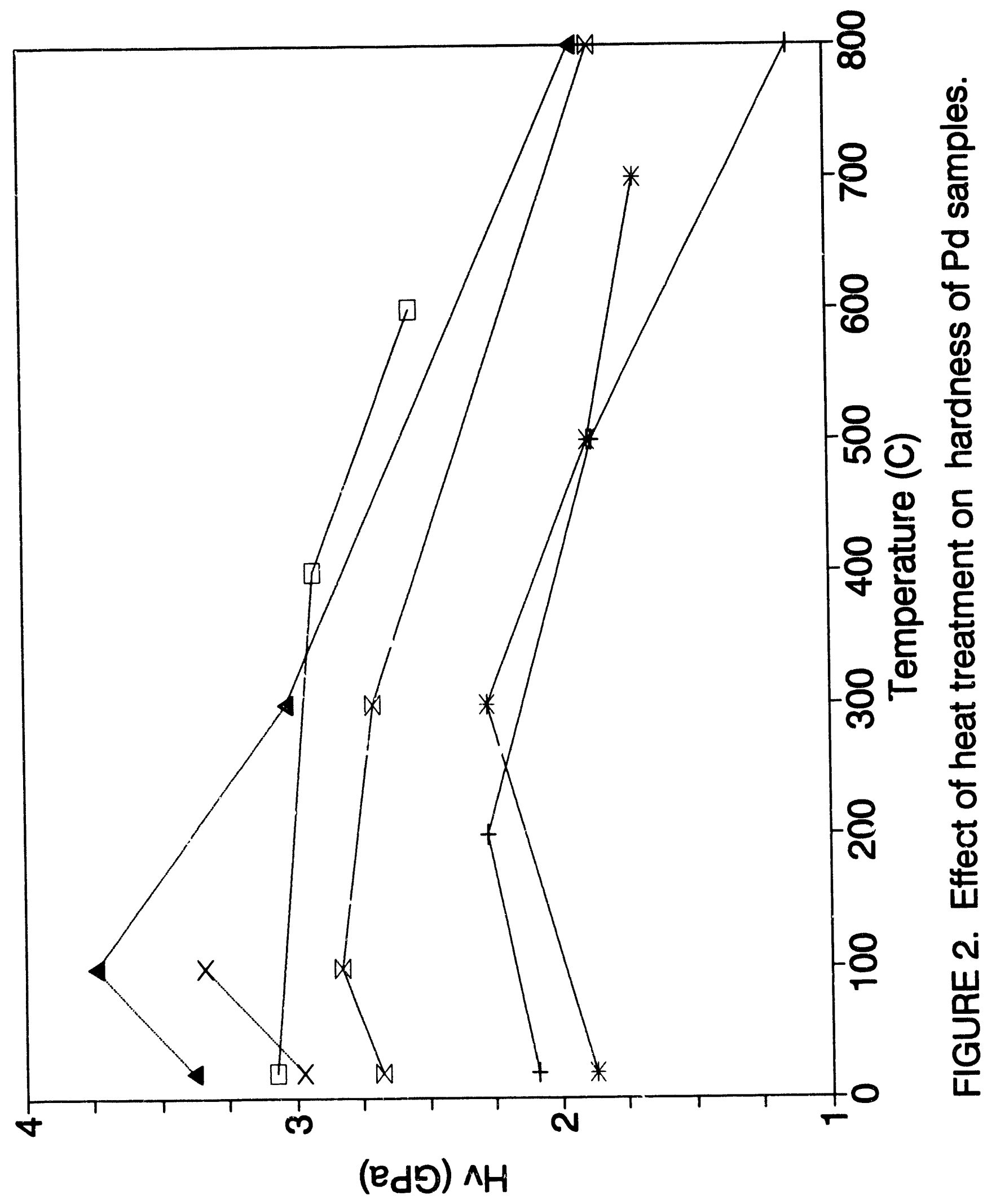




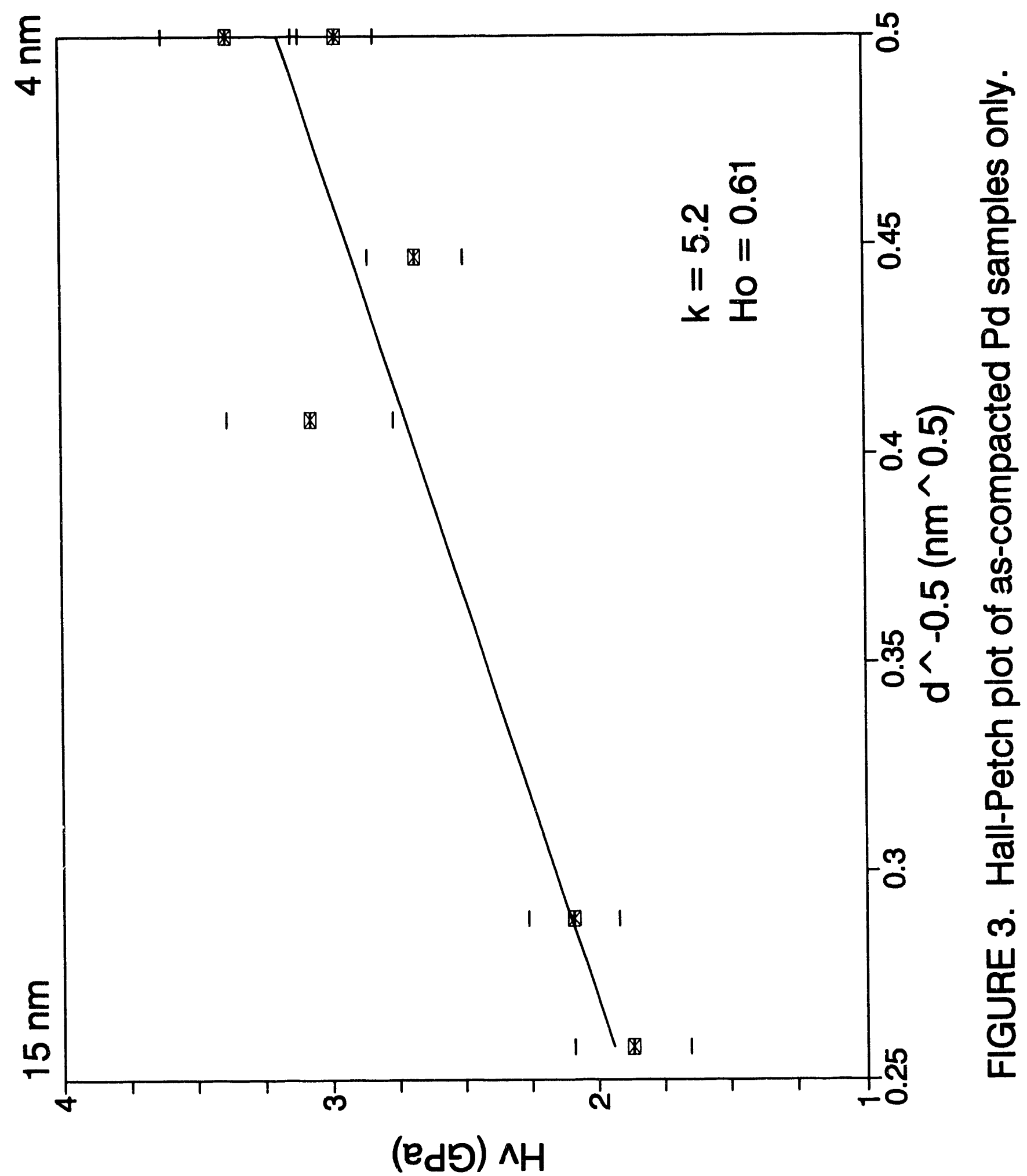




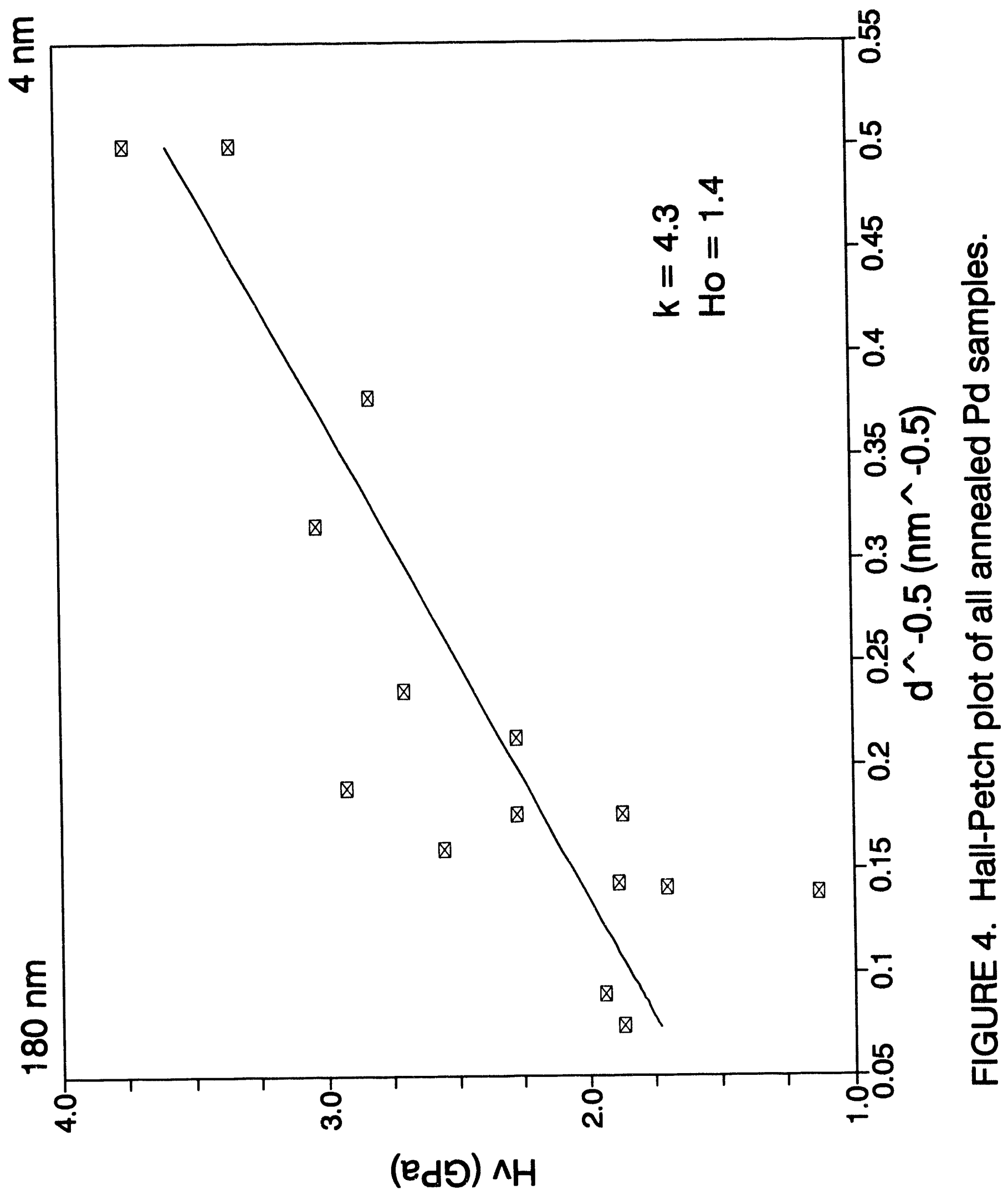




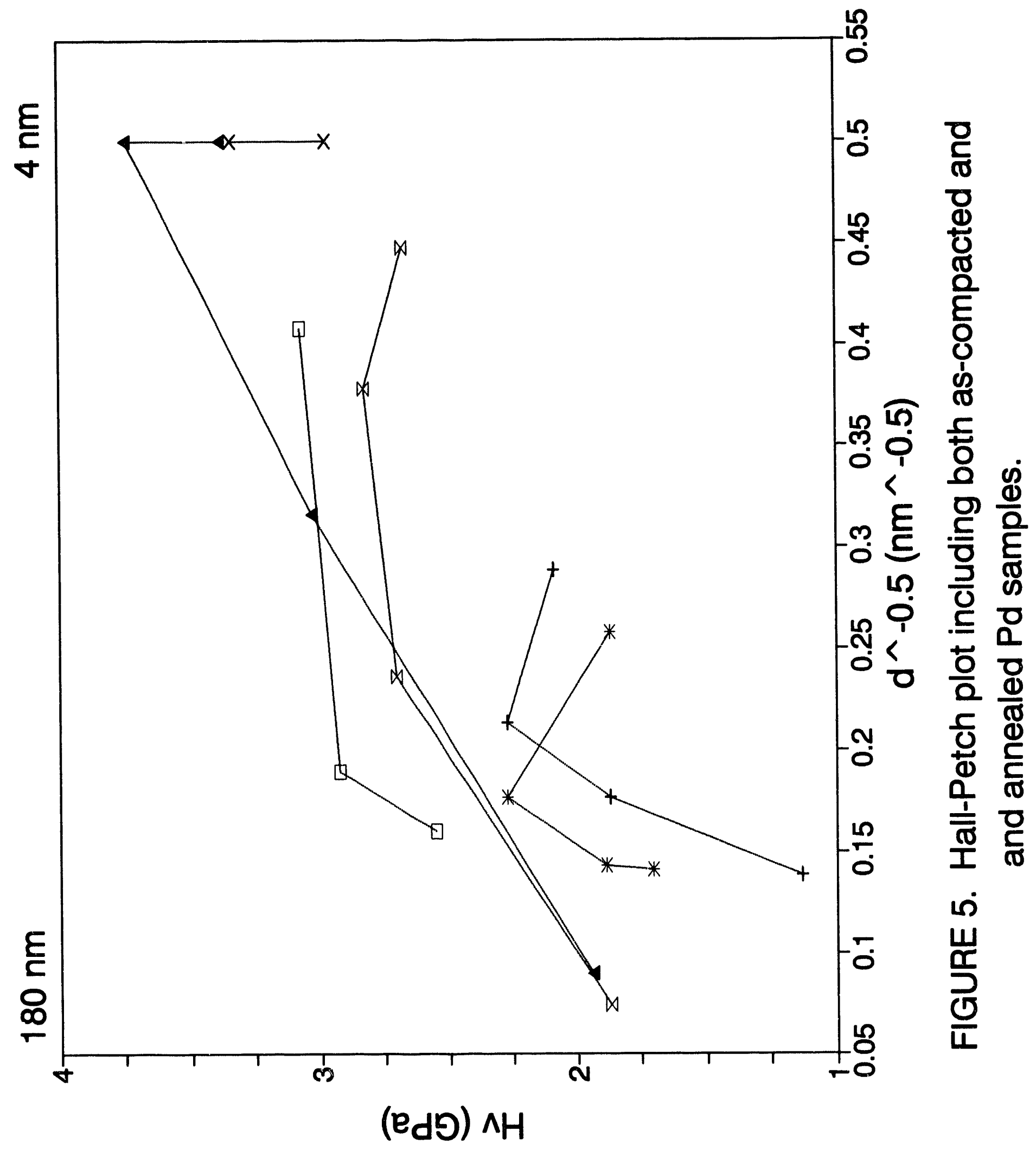




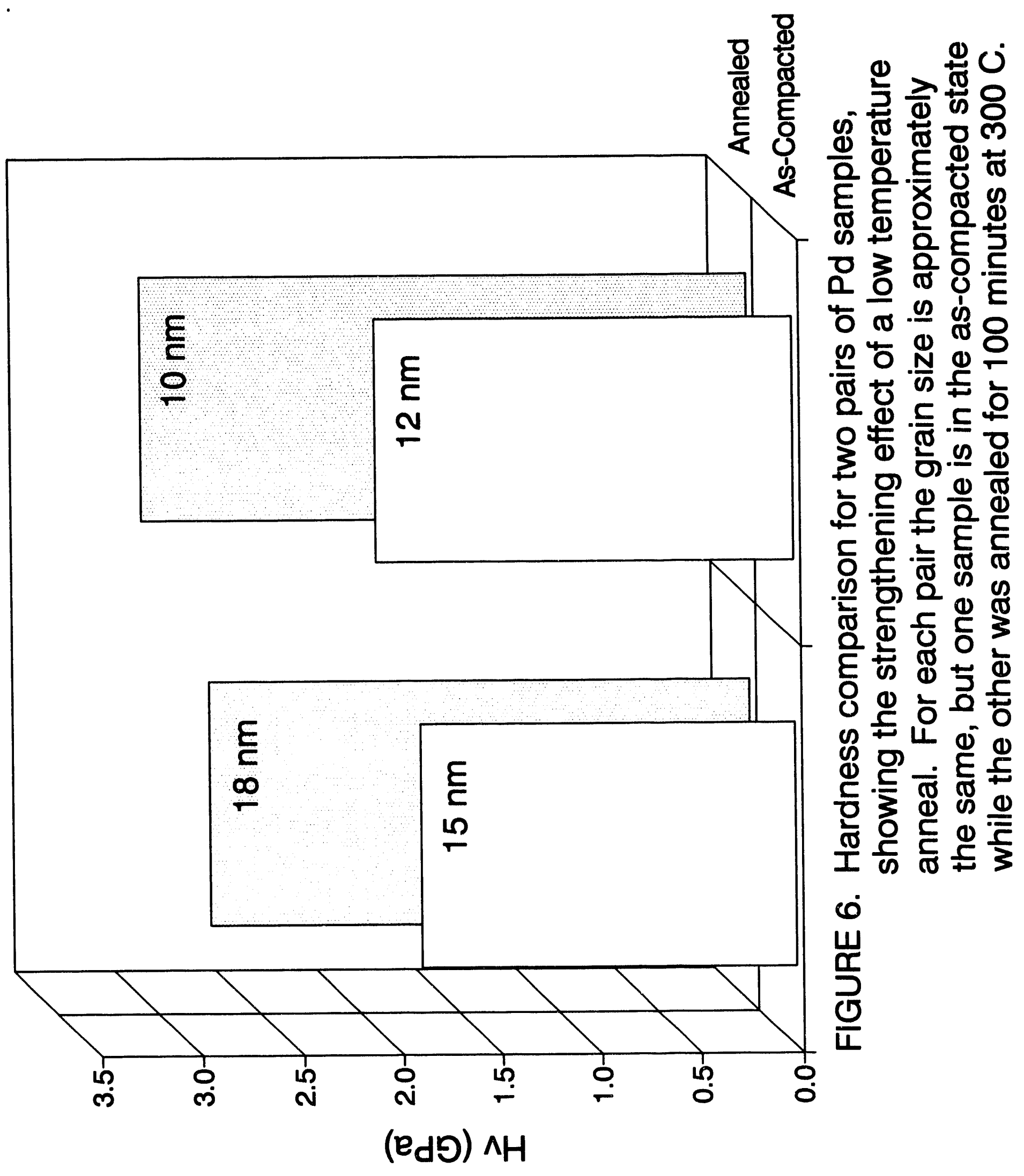




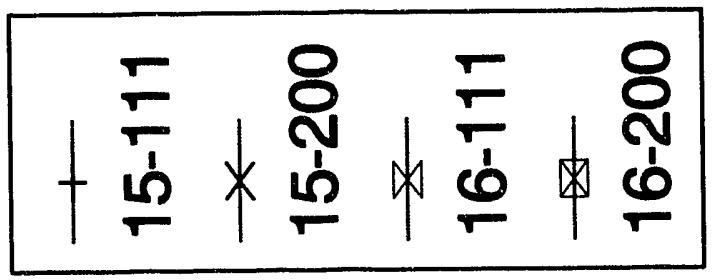

造

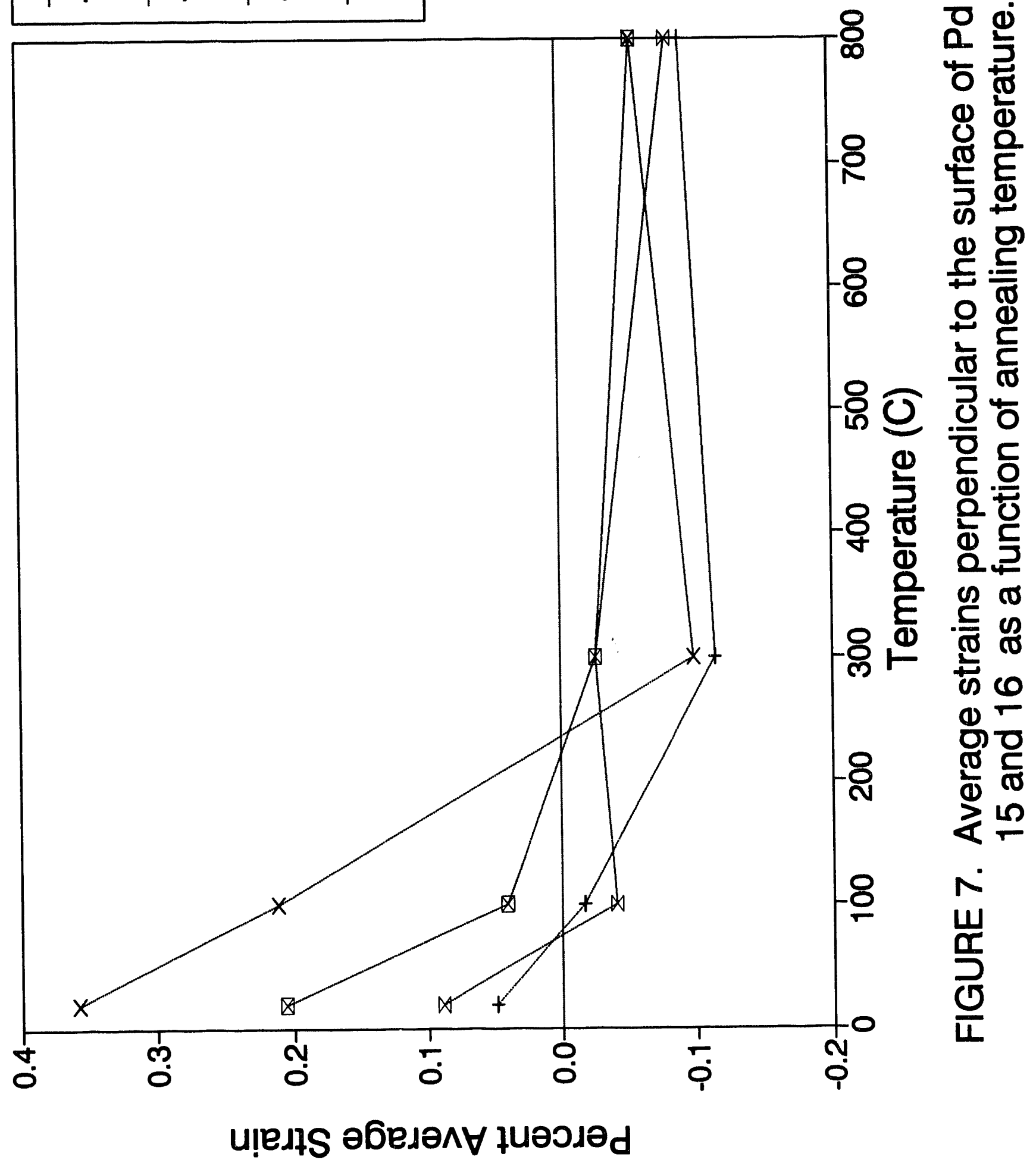




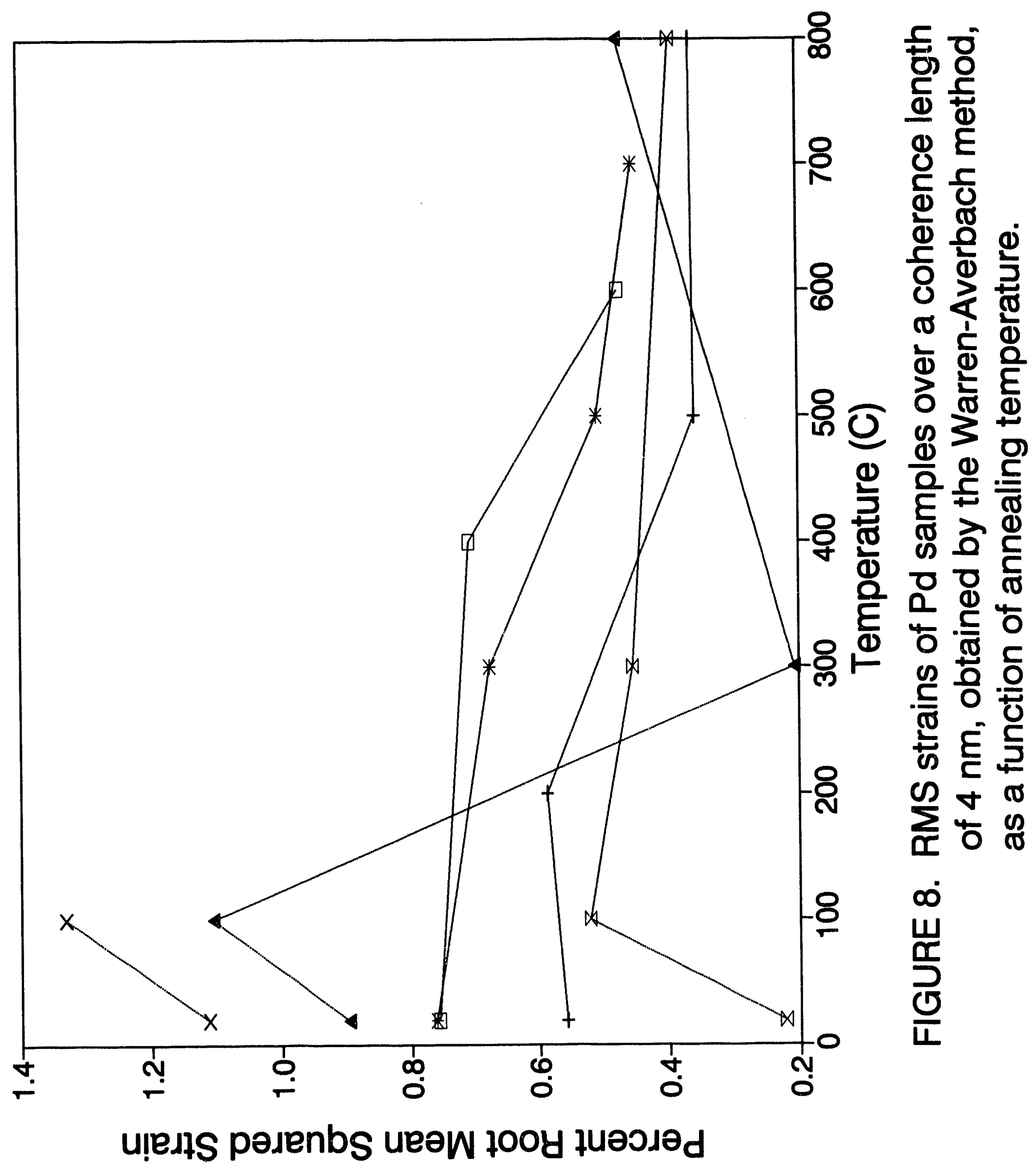




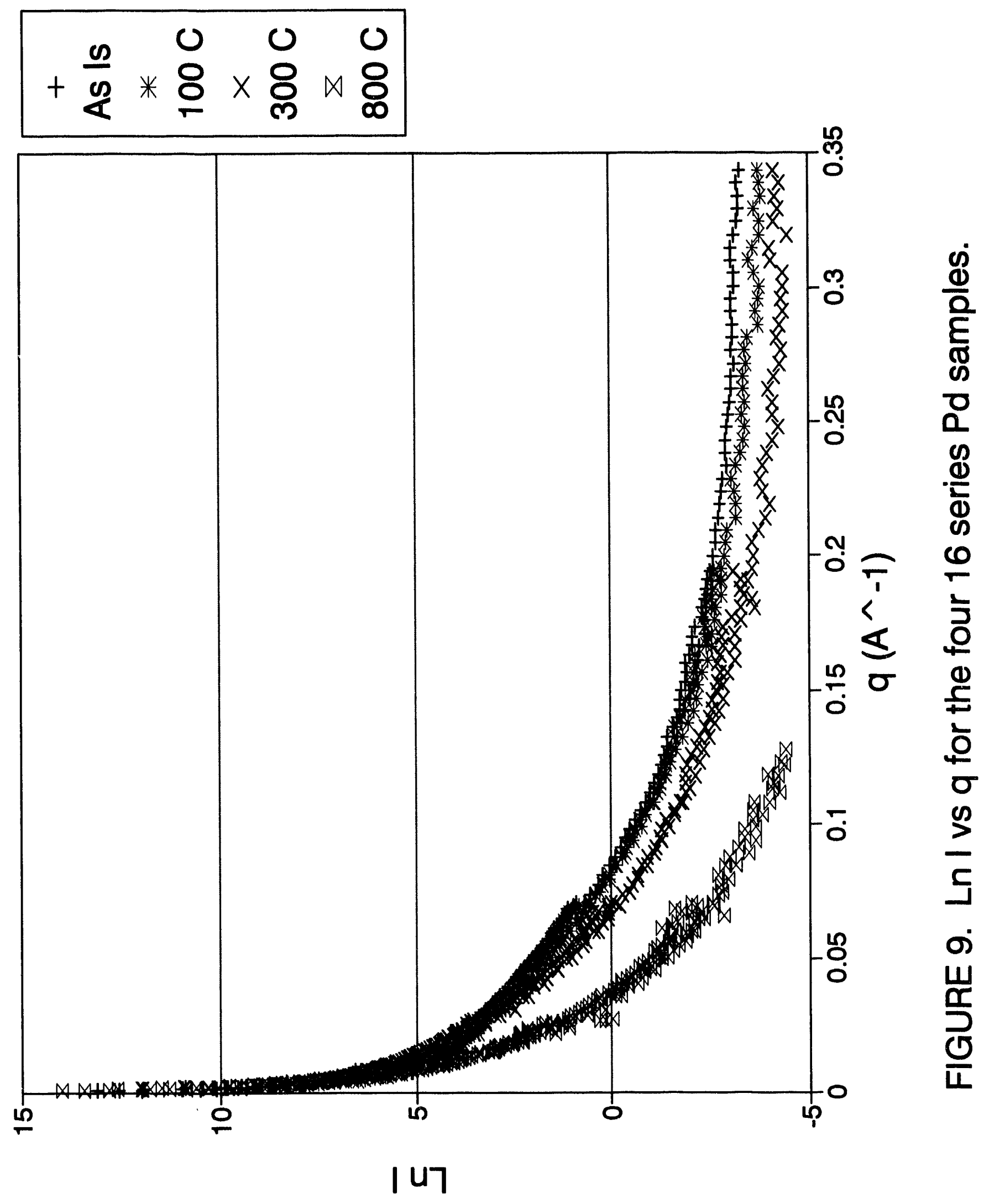




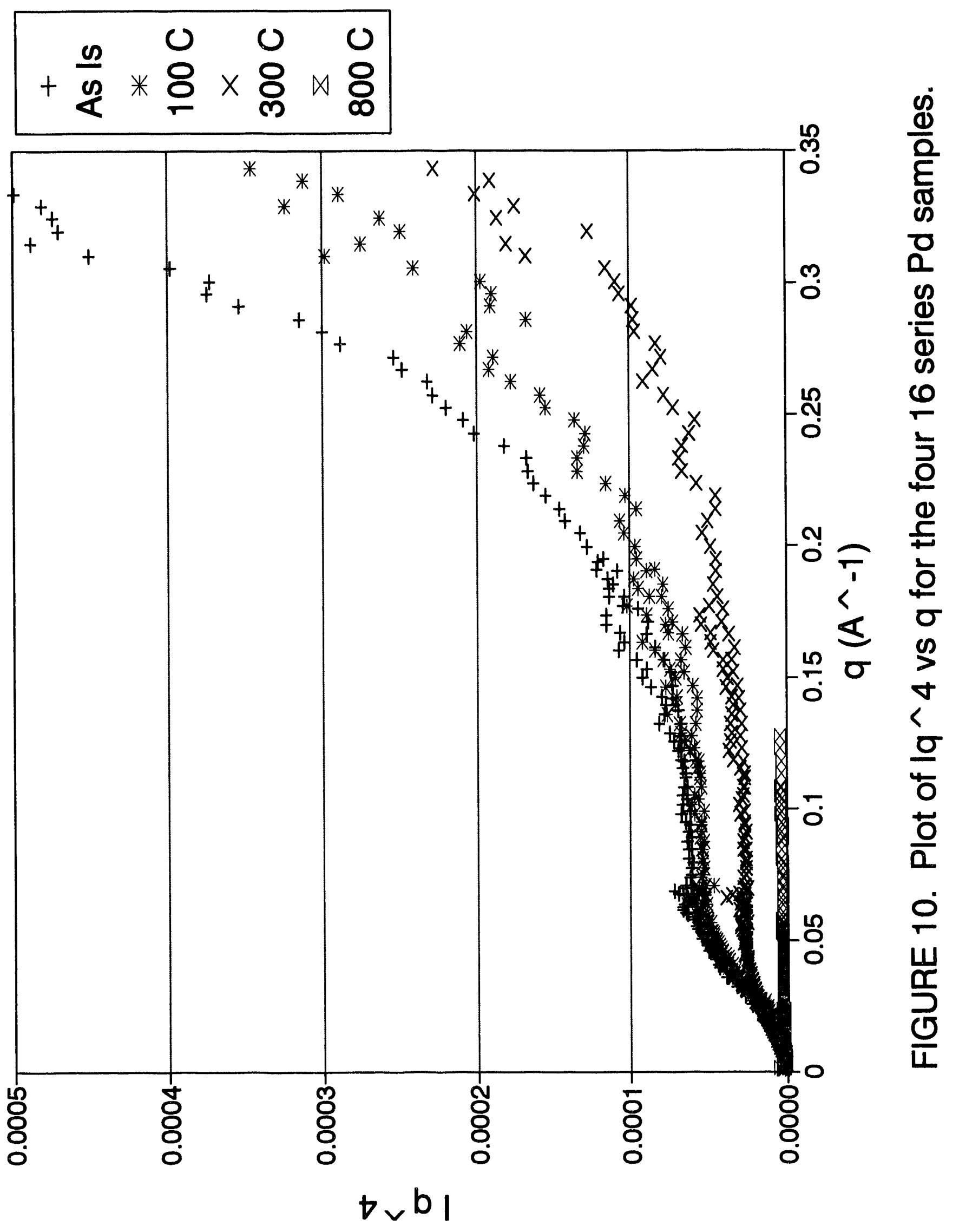




$$
+\frac{\infty}{9}+\frac{8}{8} \times 8
$$
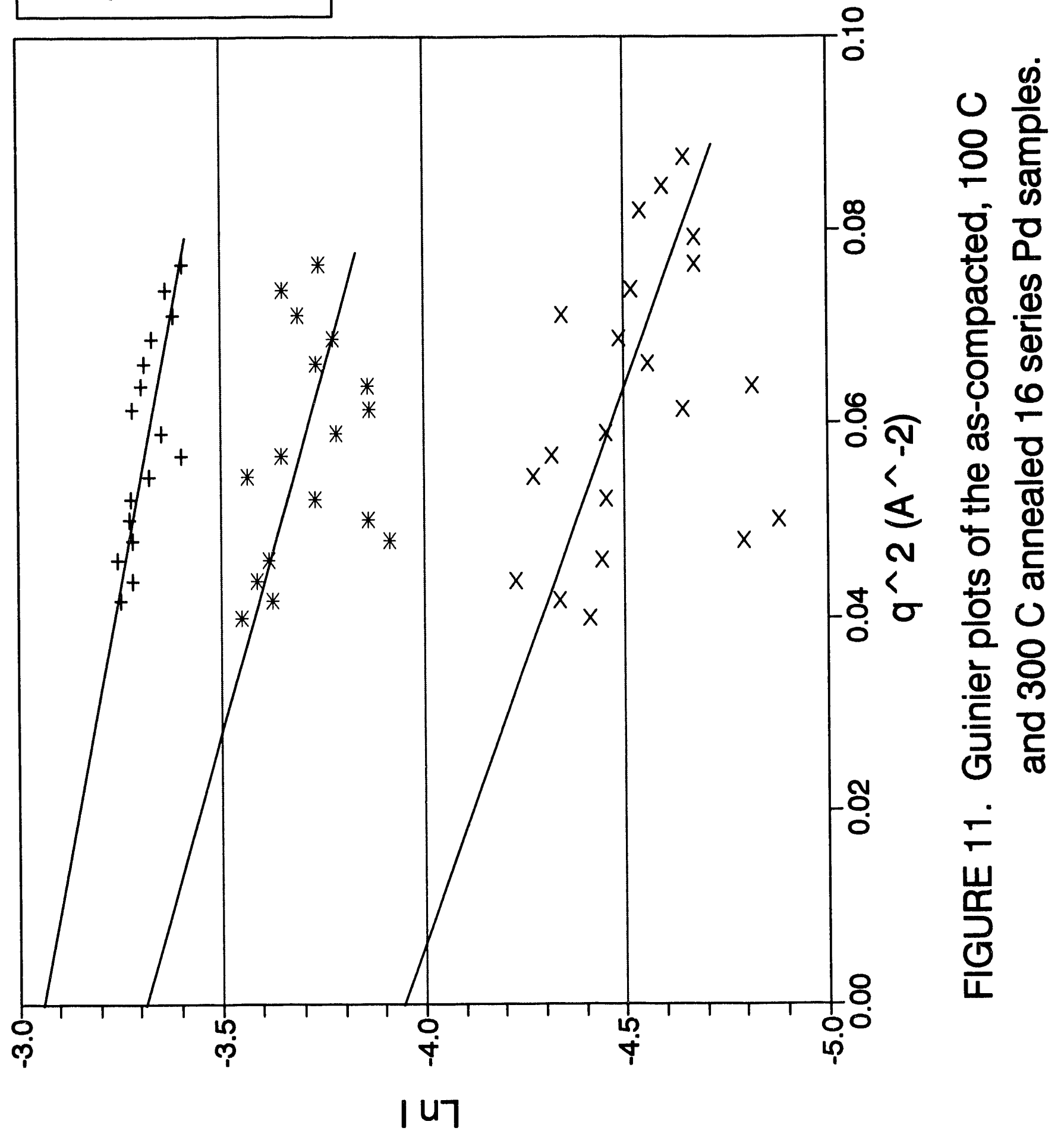


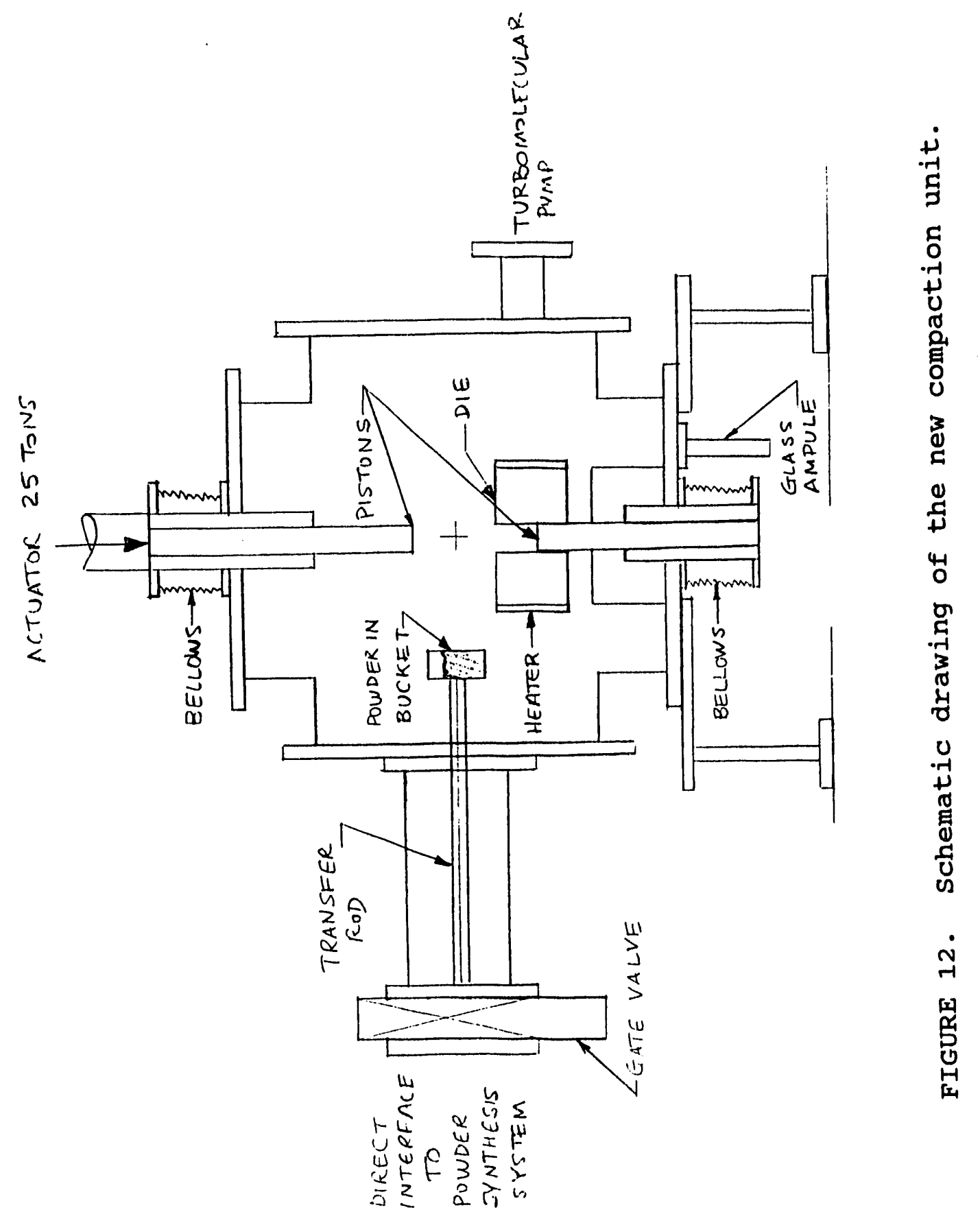



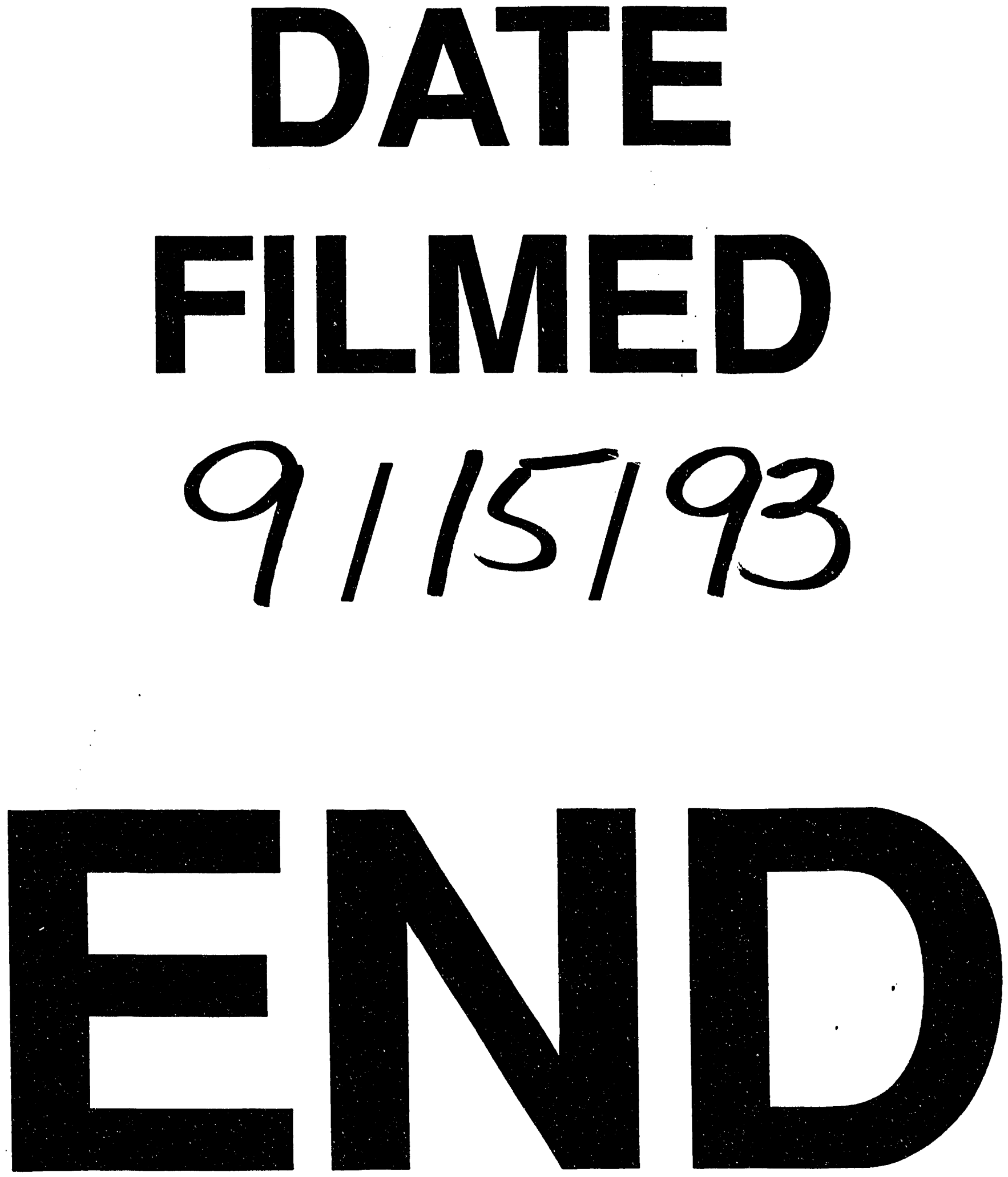
